\title{
O CICLO DA BUROCRACIA EM O CAPITÃO DE KÖPENICK
}

\section{Sabrina Siqueira ${ }^{1}$}

Resumo: Este trabalho é uma leitura da peça $O$ capitão de Köpenick como crítica ao culto da obediência e adoração ao Estado militarizado, tal qual a Alemanha no período entre as duas guerras mundiais. $O$ autor Carl Zuckmayer propõe uma reavaliação da crença de que a presença do Exército como organizador social garante ordem e justiça, pela contraposição da subjetividade humana com a objetividade militar. A personagem Wilhelm Voigt encarna 0 indivíduo destituído de sua condição de pertencente a um espaço e, assim, destituído de sua identidade. A farda militar é outra personagem, com autoridade e que pode falar por si. Na comédia, Voigt consegue sair do ciclo no qual está inserido por usar a burocracia a seu favor.

Palavras-chave: Alteridade. Carl Zuckmayer. Espaço. Identidade.

Abstract: This work is a reading of the play O capitão de Köpenick as a criticism to the Cult of obedience and idolatry of the militarized state, such as Germany in the period between the two world wars. The author Carl Zuckmayer proposes a reassessment of the belief that the presence of the army as social organizer ensures order and justice, by the contraposition of human subjectivity with the army objectivity. The character Wilhelm Voigt embodies the deprived individual of his condition of belonging to a space and, thus, deprived of his identity. The military uniform is another character, with authority and that can talk for itself. In this comedy, Voigt manages get out of the cycle in that He is iserted for using bureaucracy in his favor.

Keywords: Otherness. Carl Zuckmayer. Space. Identity.

\footnotetext{
${ }^{1}$ Estudante de Doutorado no Programa de Pós-Graduação em Letras - Estudos Literários na UFSM. E-mail: sabrinasiqueir@yahoo.com.br.
} 
A peça $O$ capitão de Köpenick foi escrita pelo alemão Carl Zuckmayer, em 1931. O texto pode ser lido como uma crítica à intensa presença militar na Alemanha no período que antecede a $2^{\mathrm{a}}$ Guerra Mundial e ao encantamento de parte da população, que acredita na ordem e no progresso advindos dessa presença. Com a derrota na $1^{\underline{a}}$ grande guerra, em 1918, e a imposição do Tratado de Versalhes pelos vencedores, a Alemanha passava por uma série de restrições, como o pagamento de reparações de guerra e a perda de territórios. A peça pode ser interpretada ainda como uma crítica à burocracia e ao culto à obediência e à autoridade, sendo que a opressão a que é submetida o protagonista se aproximada da atmosfera dos textos de Franz Kafka.

Entre as personagens principais estão o protagonista, o sapateiro Wilhelm Voigt, o capitão da guarda prussiana, Von Schelettow, o alfaiate, Wabschke, o judeu proprietário da alfaiataria, Adolf Wormser, o alcade de Köpenick, Obermüller, e sua esposa, e a irmã e o cunhado de Voigt, Marie e Friedrich Hoprecht. Podemos considerar também como uma personagem o uniforme, ou a farda de capitão, uma presença constante ao longo da peça, que aparece logo na primeira cena, quando Schelettow acabara de ser promovido capitão e está provando o novo traje na alfaiataria. A peça se passa em Postdam e Köpenick, subúrbios de Berlim.

A primeira imagem a que o público tem acesso, que corresponde à descrição do ambiente, no texto, é a vitrine da alfaiataria com uniformes militares completos, em manequins sem cabeça. $O$ fato de os manequins estarem sem cabeça remete ao fato de que, no Exército, a individualidade não importa, mas sim o posto ocupado, a patente na hierarquia dentro do Exército, designada pelo uniforme. Considerando a cabeça a parte do corpo que contém nosso "cartão de visita", o rosto, e também que abriga o cérebro, órgão responsável pelo pensamento, raciocínio, concatenação de ideias e opiniões, a mensagem dessa vitrine em primeiro plano é que os membros do Exército, quando usam a farda, não precisam de suas cabeças, pois o uniforme torna a todos iguais, tira-lhes a individualidade e Ihes subtrai a capacidade e 0 privilégio de pensar por si próprios. Também estão presentes nessa imagem de abertura fotografias da família Imperial Alemã, mostrando que o culto ao líder é algo que o país cultivou ainda antes do nazismo. $O$ intuito dessa encenação do poder, em que fardas encantam civis e fotos de líderes ocupam o âmbito do privado, é a 
captação da atenção das massas e a construção de uma identidade militar atrelada à identidade nacional, como forma de reafirmar o poder do Estado militarizado.

A partir da personagem Schlettow, Zuckmayer contrapõe a subjetividade humana e a objetividade militar. O capitão aponta ao alfaiate que a distância entre os botões traseiros da farda não está correta, porque isso é o que lhe diz sua intuição, ainda que não os esteja visualizando. Essa personagem que dá valor ao que diz sua individualidade, ainda que utilize a informação para os detalhes do fardamento, dá mostras de que não serve mais para o regime regrado do Exército, em que tais impulsos inconscientes de natureza psico/individual não têm espaço. Ainda que tenha tido prestígio no Exército e chegado a capitão, a personagem agirá por impulso em um momento em que se encontrava vestido como civil, envolvendose em uma briga para defender a honra da instituição à qual pertencia e impedir que um soldado fardado proceda indevidamente. Esse "agir por impulso" provoca sua derrocada do grupo, onde somente a ordem e a ação obediente são toleradas. A valorização dos detalhes na farda esboça um critério de exclusão: os sujeitos que pertencem ao Exército vestem-se com a precisão e o cuidado de detalhes que permite excluir o "outro". Quanto maior for a diferenciação desse "outro", maior a valorização dos pertencentes ao grupo, por isso a insistência com os milímetros entre cada botão.

A exemplo do autor Zuckmayer, que participou do Exército alemão e, com ele, da $1^{\text {a }}$ Guerra Mundial, a personagem Schlettow faz crítica à rigidez do serviço militar, conforme se infere da seguinte fala, dirigida a outra personagem que não é militar: "Se no quartel contestasse tanto, nunca sairia do calabouço" (ZUCKMAYER, 1957, p. 8). A crítica se estende à postura exigida pela instituição, que é repetidas vezes lembrada por Wormser ao filho: "É a postura que dá o serviço ao ar livre e a guarda de nosso imperador [...] Willy, te endireita. Não agüento ver como estás parado Se continuares assim, nunca te aceitarão no serviço militar" (idem, p.9). Wormser, o dono da alfaiataria que sonha com a carreira militar para o filho, mostra admiração pelo regramento do Exército alemão, o que é irônico por se tratar de um judeu: "Frederico o Grande, nosso regramento de exercícios e o imperativo categórico, são as três coisas em que jamais poderão se igualar a nós o mundo inteiro" (idem). 
Em Wormser e em Voigt, Zuckmayer delineia personagens deslocadas, mas (e talvez por isso) com a habilidade de entender o "outro". O judeu da alfaiataria, por exemplo, não se associa ao mais forte necessariamente por falta de criticidade, mas porque esse é o caminho mais fácil para manter-se confortável naquela sociedade excludente. $O$ encantamento com a cultura militarizada aparece também no discurso do cunhado de Voigt, Hoprecht, e de Obermüller, que será enganado pelo falso capitão. Esse último acredita que

O grande em nosso país é a ideia do exército popular em que cada um ocupa o lugar que the corresponde de acordo com nossa estrutura social. Via livre ao homem capaz. Esse é o lema alemão. A ideia da liberdade individual se funde com a ideia constitucional formando um todo amplamente evolucionista ${ }^{2}$ (ZUCKMAYER, 1957, p. 34).

Mas a quantidade de regras impostas por essa sociedade militarizada não garante a felicidade. Antes disso, promove injustiças sociais por meio da burocracia. Como o que acontece com Wilhelm Voigt, que recebe uma pena injusta de 15 anos por ter roubado 300 marcos, quando ainda é jovem. Sai da Alemanha depois de solto, mas a saudade da pátria o faz retornar. Ao voltar, não consegue emprego no ofício de sapateiro porque não tem endereço para comprovar nas entrevistas de emprego. E não consegue um local para morar porque não tem emprego. $E$ também não consegue um passaporte porque não tem endereço ou emprego.

Voigt encarna o indivíduo destituído de sua condição de pertencente a um espaço, que é sua terra natal, e que está atrelado à sua composição identitária. A personagem vive o que se pode comparar a um "drama kafkiano", tomando por referência os textos do escritor tcheco Franz Kafka, como O Processo, publicado em 1925, e a parábola "Diante da Lei", em que há referência ao Estado, à burocracia, à máquina estatal arruinando a liberdade dos cidadãos. Nas sociedades dramatizadas por Kafka e em $O$ capitão de Köpenick, a estrutura estatal deveria garantir o funcionamento dos órgãos públicos de forma a beneficiar o cidadão, mas na prática a burocracia impede que as pessoas exerçam seus direitos e que sejam felizes.

\footnotetext{
${ }^{2}$ Tradução do Espanhol minha, como as outras traduções para o Português ao longo deste texto.
} 
Considerando que a identidade está atrelada ao autorreconhecimento, e este à identificação do sujeito com o espaço ao qual pertence, a personagem encontra-se presa em um ciclo construído pelo sistema burocrático imposto pela militarização e, assim, destituído de sua identidade:

Mas eu tinha saudade ${ }^{3}$. Na Bohemia, todos são diferentes e também falam um idioma diferente. Como cada ser humano tem uma língua mãe, porque essa se tem, ainda que não tenha outra coisa no mundo, eu voltei. [...] Se não estou registrado, não consigo trabalho, e enquanto não tenha trabalho, não posso registrar-me. [...] Tem que haver um lugar a que um sujeito pertença. (ZUCKMAYER, 1957, p. 14-15-16).

O autorreconhecimento está diretamente associado à capacidade de exercício da alteridade. A alteridade, por sua vez, está ligada diretamente a sua identidade, ou seja, tem relação com o reconhecimento e o autorreconhecimento de um indivíduo em relação a um grupo social. Segundo Eric Landowski (2002), o sujeito adquire consciência de si mesmo, de sua presença no mundo, a partir da diferença, independentemente de ordem, caráter ou variação. Só a diferença "permite constituir como unidades discretas e significantes as grandezas consideradas e associar a elas, não menos diferencialmente, certos valores, por exemplo, de ordem existencial, tímica ou estética" (LANDOWSKI, 2002, p. 3). Tanto em relação ao mundo que o cerca, quanto em relação a si mesmo e ao outro, o sujeito, dessa mesma forma, constitui-se pela diferença. $O$ sujeito teria necessidade de um outro para alcançar um sentido de existência própria. Isto porque o sujeito atribui algo específico a esta diferença, um conteúdo determinado ou sugerido, justamente o que segrega o eu e o outro. Dessa forma, o sujeito define a si mesmo, ou tenta definir, a partir de uma imagem autoconstruída e também considerando a imagem que este outro envia de volta ao eu. Como demonstra Landowski:

[...] um sujeito não pode, no fundo, apreender-se a si mesmo enquanto "Eu", ou "Nós", a não ser negativamente, por oposição a um "outro", que ele tem que construir como figura antitética a fim de poder colocar-se a si mesmo como eu contrário: "O que eu sou é o que você não é" (LANDOWSKI, 2002, p. 25).

\footnotetext{
${ }^{3} \mathrm{Na}$ versão em Espanhol, aparece a palavra "nostalgia" onde traduzi como "saudade". 
O espaço onde o sujeito alicerça o constructo de sua identidade, onde reforça seus laços culturais, colabora para a formação identitária individual. Todas as identidades estão localizadas no espaço e no tempo simbólicos, ou seja, o lugar do sujeito, no momento histórico ao qual pertence. Quando essas características se diluem, alteram-se também as representações das identidades. Conforme Hall (2006), o tempo e o espaço são as coordenadas de todos os sistemas de representação. O passado é um meio de ligar o espaço e o tempo, inserindo o fazer humano na continuidade do passado, presente e futuro. Landowski (2002) compreende o tempo como um "agora" e o espaço como um "aqui", tal caráter funciona como um campo de diferenças entre o eu e o outro. Nesse âmbito, cabe à distância do aqui/agora em relação a todo o resto, de outros lugares e outros momentos, revelar ao indivíduo ele mesmo, à medida que reconhece seu espaço e seu momento:

[...] só há espaço-tempo em função da competência específica de sujeitos que, para se reconhecerem, e antes de mais nada, para se constituírem a si próprios enquanto tais, têm de construir também, entre outras coisas, a dimensão "temporal" de seu devir e o quadro "espacial" de sua presença para si e para o Outro (LANDOWSKI, 2002, p. 67).

Para Voigt, o tempo de prestar serviço militar passou enquanto cumpria pena, e com isso a chance de manter-se inserido na Alemanha de então. Nesta peça de Zuckmayer, o Exército controla a sociedade e instaura a burocracia em todos os órgãos públicos, incluindo a cadeia, onde o sapateiro aprende as táticas militares, na condição de exercício para os detentos. O diretor da cadeia presta tamanha devoção à instituição que chega a ver nela algo de sublime e bendito: "a instituição bendita do serviço militar obrigatório criou, dentro de nosso povo, por meio do seu exército estável, uma força viva que também nos tempos de paz constitui uma garantia moral em apoio de uma saúde física e espiritual" (ZUCKMAYER, 1957, p. 37).

A farda encarna a autoridade e fala por si. Sem ela, o capitão, apesar de ostentar tal patente, fica desprovido de coragem para tomar iniciativas, inclusive no campo pessoal: 
Bem, de uniforme a coisa não vai mal. O uniforme dá aprumo, segurança. Enfim, um se sente como outro. Assim, de civil, me sinto... Como vou dizer? Como uma salsicha sem mostarda. [...] Nossa família tem mais de cem anos de tradição militar e nosso lema tem sido sempre: jamais uma mancha sobre o uniforme (ZUCKMAYER, 1957, p. 20).

Apesar dos lampejos da intuição, o capitão não aprende a agir fora do regramento militar, sentindo-se desconfortável em trajes civis e não sabe se portar em eventos sociais, rigidez de conduta que seu amigo médico constata como comum ao povo alemão: "Nós alemães tornamos a nós mesmos a vida difícil" (Zuckmayer, 1957, p. 21). Schlettow associa a condição humana à ligação com o Exército, que se materializa pelo uso da farda, uma opinião replicada por outras personagens ao longo da peça. Sem o uniforme, essa personagem contraditória por ser militar e escutar a intuição não se vê como ser humano: "É uma conseqüência da nossa educação, segundo creio. [...] 'Estamos a serviço'. Isto nos devolve à condição humana" (idem). Esses valores se estendem a outras personagens, e a polícia não dá ouvidos à explicação de Schlettow de que ele é um capitão porque, naquele momento, ele não está usando o uniforme: "Isso qualquer um diz. Sem os galões, para mim não és mais que um vulgar civil” (idem, p. 24). E, quando lhe entrega o uniforme de capitão que estava tendo os lugares dos botões reposicionados nas medidas exatas, o alfaiate comenta que o oficial "não terá mais intuições" (idem, p. 27), posto que a farda eliminaria este resquício de humanidade que teimava em surgir na autoridade militar.

Nas palavras do judeu dono da alfaiataria, ironicamente o grupo que seria pouco depois cientificamente taxado como inferior pelo nazismo, a hierarquia militar tem desenvolvimento paralelo ou associável ao da espécie humana: "Do cabo em diante começa o darwinismo, mas a espécie de homem começa com o tenente" (ZUCKMAYER, 1957, p. 32). O discurso reforçado ao longo da peça, e que é apreendido por Voigt, é de que quem não é militar, naquele espaço, é inferior. Por conseguinte, essa personagem apreende que, com o uniforme, poderia fazer qualquer coisa. O discurso do que é certo, sem um uniforme militar, não consegue ser validado. Mas o que é errado, mesmo uma farsa, se endossada por uma farda, 
torna-se o certo e é aceito. Sendo assim, o valor humano na sociedade militarizada está em baixa, e o que está em alta é o discurso que emerge do símbolo militar.

O uniforme é o que diferencia civis de militares, e militares entre si, de acordo com a hierarquia. O culto a essa autoridade provoca a crença de que o uniforme tem algo mágico. É justamente essa crença que promove o embuste, quando um sujeito deslocado na sociedade mesmo enquanto civil, destituído do pertencimento social de cidadão, incorpora autoridade ao vestir um uniforme. Voigt se vale do entendimento de que a farda fala mais alto que a humanidade e que a justiça, e aproveita a oportunidade de comprar o uniforme de capitão, já manchado e expuído, quase três décadas depois de ter tido seus botões reposicionados, para buscar liberdade dentro do espaço em que já não se reconhece.

Kathryn Woodward, em Identidade e diferença (2009), explica que a identidade de alguém depende de algo fora dela para existir, depende do que se difere dela. A identidade de um sujeito se distingue por aquilo que ele não é, sendo, portanto, um conceito marcado pela diferença. Uma diferença que é marcada pela exclusão. Como acontece com os militares do texto de Zuckmayer, que utilizam a farda para marcar sua posição social e acentuar a diferença entre eles e os que não fazem parte do grupo do Exército, a autora considera que há uma associação entre a identidade da pessoa e as coisas que essa pessoa usa: "A identidade é marcada por meio de símbolos" (SILVA, 2009, p. 9).

O diálogo entre Hoprecht e Voigt demonstra a contradição entre a ingenuidade do cunhado que, mesmo não tendo recebido a promoção que the era devida, crê no valor humano associado ao pertencimento a uma ordem, e no esclarecimento da injustiça em que vive do sapateiro, que está cansado de ter a sua humanidade tolhida pela burocracia do Estado militarizado.

Voigt - A ti não promoveram... a mim me removeram. A cada um o que lhe cabe. Não é assim? [...] Não é questão de sorte. Nem boa, nem má. É uma injustiça. Mas não te aflijas, Friedrich. Há mais injustiças no mundo. Injustiças grandinhas e crescidinhas. Eu agora sei. [...] $E$ que faço depois? Isso [resignar-se] todavia não me converterá em ser humano.

Hoprecht - Um ser humano, um ser humano. Um ser humano és quando agrupado dentro de uma ordem humana. Viver, ah, isso também fazem os percevejos. 
Voigt - Aí está! Os percevejos vivem. E sabes por quê? Porque no mundo do percevejo vem primeiro o percevejo e depois a ordem dos percevejos, e conosco é o contrário.

Hoprecht - É porque tu não queres te subordinar. Quem quer ser tratado como homem tem de se subordinar. [...] Nossa ordem é boa. Observa as tropas, como marcham em fila (ZUCKMAYER, 1957, p.57).

Landowski (2002) menciona que ser um sujeito em si mesmo não é apenas afirmar-se como o que o outro não é. Antes, trata-se de "captar o mínimo de coerência que dá sentido e unidade ao devir que faz com que cada um seja, individual ou coletivamente, o que é”. (LANDOWSKI, 2002 p.26). O outro, dessa forma, é também uma figura emblemática marcada pelo vazio, ou por algo de ausente, em que o sujeito procura negativamente se reconhecer. Ou seja, o outro é um algo no qual o sujeito busca o reconhecimento, preenchendo estes espaços ausentes com algo de si mesmo. Considerando o constructo da identidade como atrelado ao espaço/lar do indivíduo, Hall (2006) cita o filósofo Roger Scruton, para quem

[a] condição de homem exige que o indivíduo, embora exista e aja como um ser autônomo, faça isso somente porque ele pode primeiramente identificar a si mesmo como algo mais amplo - como um membro de uma sociedade, grupo, classe, estado ou nação, de algum arranjo, ao qual ele pode até dar um nome, mas que ele reconhece instintivamente como seu lar (Scruton, 1986, p. 156 apud HALL, 2006, p. 48).

Devido a essa necessidade de se reconhecer em seu espaço, o discurso de Voigt evolui em busca de, primeiro, afirmar sua identidade em Berlim, onde falam seu idioma, e depois, recriar uma identidade em um novo espaço, para o qual pretende escapar. O cunhado de Voigt, o judeu dono da alfaiataria e o diretor da cadeia são as personagens que, em diferentes níveis de consciência, mais fortemente demonstram a crítica do autor ao culto da obediência. São personagens que, imersos na adoração de um sistema que promete a ordem e a justiça, não percebem as oportunidades perdidas pela injustiça instaurada. Aproximando a obra e o que sabemos da História, a cegueira que atinge essas personagens, conveniente (para o judeu) ou não, permitiria que esse Estado militarizado ganhasse força e tivesse influência decisiva no conflito mundial iniciado em 1939. 
Uma das características do período entre guerras, na Alemanha, foi um forte revanchismo deixado no povo alemão por conta dos territórios perdidos e de outras imposições do Tratado de Versalhes. A sensação de que só um novo conflito armado, de grandes proporções, tornaria o país grande novamente, está presente em $O$ capitão de Köpenick. $O$ discurso de algumas personagens deixa entrever 0 saudosismo pela prática da guerra e o conseqüente fortalecimento do Exército como formas de melhoria de vida para os alemães, ou para parte deles, como Hoprecht, que então poderia ter sua promoção de sargento efetivada.

Para Voigt, a consciência da injustiça no Estado militarizado, para ele refletida na perda de sua identidade alemã e consequente destituição de seu lugar no mundo, não se dá de uma hora para outra. Quando a ação da peça inicia, Voigt é um rapaz jovem, e a virada promovida pela sua ponderação acerca dos males da burocracia acontece quando ele tem quase sessenta anos. $O$ entendimento de que a ordenação milimétrica dos botões das fardas militares não se traduz em ordenamento e justiça social para todos começa quando é preterido para o emprego na fábrica de sapatos, apesar de sua experiência como sapateiro. Ele percebe outros aspirantes sendo contratados sem possuírem experiência alguma, apenas por terem prestado serviço militar. Voigt entende então que os valores estão distorcidos naquela sociedade, porque entender das ferramentas de que se utiliza um sapateiro não importa para o contratante da fábrica de sapatos, que só pergunta sobre a experiência militar dos candidatos. Conforme Woodward, "todas as práticas de significação que produzem significados envolvem relações de poder, incluindo o poder para definir quem é incluído e quem é excluído" (SILVA, 2009, p. 18). Reforçando que as identidades são fabricadas pela marcação da diferença, a autora explica que essa marcação ocorre

tanto por meio de sistemas simbólicos de representação quanto por meio de formas de exclusão social. [...] Nas relações sociais, essas formas de diferença - a simbólica e a social - são estabelecidas, ao menos em parte, por meio de sistemas classificatórios. Um sistema classificatório aplica um princípio de diferença a uma população de uma forma tal que seja capaz de dividi-la (e a todas as suas características) em ao menos dois grupos opostos - nós/eles [...]; eu/outro (SILVA, 2009, p. 39-40).

A sinceridade com que Voigt responde ao empregador, em oposição à obediência dos candidatos que prestaram serviço militar, soa como atrevimento. $O$ 
sujeito que não esteve no Exército ainda pensa pela sua cabeça e responde com o inesperado, com uma resposta que foge ao protocolo. Mas, mais uma vez, o sapateiro vê-se enredado no ciclo que o impede de conseguir emprego porque estava preso enquanto devia estar no Exército, e não tendo emprego fica impedido de conseguir moradia.

Knell- Tem que apresentar seu registro policial ou, em sua falta, seu passaporte.

Voigt - Não o consigo enquanto não tiver trabalho.

Knell - Sem seus documentos em dia não podemos empregá-lo. Aonde iríamos parar se não fôssemos rígidos nesse aspecto? Aqui há ordem! Todo mundo tem que documentar devidamente sua identidade. Se tivesse feito serviço militar, compreenderia perfeitamente.

Voigt (tranquilo e seco) - Pensei que isto era uma fábrica, mas parece que é um quartel (ZUCKMAYER, 1957, p. 38).

Voigt vive preso em um ciclo burocrático como em um drama kafkiano até três quartos da peça, quando consegue usar a burocracia para virar o jogo. Como o texto de Zuckmayer trata-se de uma comédia, a personagem descobre uma brecha, que foi a possibilidade da compra do uniforme de capitão, para conseguir o passaporte e finalmente ter a chance de escapar do lugar que já não lhe pertence. Quando retorna a Berlim, na juventude, Voigt volta pela necessidade humana de estar entre iguais, entre aqueles que reverberam sua identidade, pela cultura e pela língua. Mas o que ele encontra entre os compatriotas é um povo diferente do que havia deixado, um povo "hipnotizado" pela burocracia e regramento militar. Se o drama do sapateiro pode ser comparado às histórias opressoras de Kafka, a personagem em si nada tem de kafkiano. Enquanto os protagonistas do escritor tcheco sucumbem sem entender o mal que Ihes aniquilou, Voigt descobre o funcionamento daquela sociedade militarizada e consegue subverter a ordem a seu favor. Destituído de um lugar, ele clama por sua condição humana e o direito à liberdade: "Só quero minha tranquilidade e minha liberdade" (ZUCKMAYER, 1957, p. 77).

O entendimento é de que o uniforme abre portas e que o aprendizado das táticas militares na cadeia, somado ao linguajar adequado e ao conhecimento das estratégias podem fazer com que o sapateiro sem-teto passe por capitão e dite ordens. Quando disfarçado, a única a questionar o comportamento do recém 
chegado capitão é a esposa do intendente que está sendo preso, uma pessoa que não faz parte diretamente do Exército e, por isso, não está tão bitolada a obedecer a hierarquia militar. A ideia repetida ao longo da peça de que a farda possui algo de mágico e muda o homem que a possui é ratificada ao final. Mesmo tendo confessado sua mentira para conseguir o passaporte, Voigt é tratado com o respeito que nunca tivera de seus compatriotas enquanto tentava honestamente dar um rumo a sua vida. Mas a amabilidade do inspetor ainda não permite que veja Voigt como realmente é, que fique ciente da justiça de suas necessidades e cojita que o sapateiro seja um doente mental. Comicamente, Voigt se mostra lúcido e cita Napoleão, figura recorrentemente inspiradora de lunáticos na literatura e no cinema: "A sorte é parte do talento militar. Já dizia Napoleão".

\section{Considerações finais}

O capitão de Köpenick nos leva a ponderar sobre o que há de humano em um indivíduo e o quanto esta humanidade está associada à utilidade dessa pessoa no meio em que vive. Algumas personagens da peça, encantadas com a glória e a valia do Exército, atribuem a condição humana ao pertencimento à instituição, que tem seu valor amplificado na Alemanha, no período entre guerras, espaço/tempo dessa narrativa. Com esta comédia, Zuckmayer mostra o autoritarismo e a prepotência de uma ordem que não é feita para beneficiar o ser humano, mas para aniquilar o que há de humano e produzir autômatos, treinados em idolatrar o regramento militar.

A política nacionalista, com culto à imagem do líder, já era forte na Alemanha de 1931, quando Zuckmayer escreve O capitão de Köpenick. Essa política torna a nação mais forte enquanto grupo unido pelo militarismo e coloca em movimento uma dinâmica psicológica do pertencimento, válida a princípio para todos os filhos da Pátria, mas, conforme o texto do autor sublinha, excludente para muitos, inclusive para alguns alemães. Por trás da identidade nacional de grupo há um mecanismo de exclusão do mais fraco. Nessa comédia, o pertencimento ao Exército e os milímetros que separam os botões do uniforme de capitão são ferramentas de exclusão e de validação do sistema vigente. 
Os apontamentos de Landowski esboçam a ideia de reconhecimento do sujeito no outro, a fricção entre alteridade e identidade, a problemática da interdependência do eu e do outro, pois "manter-se em relação ao Outro, como manter-se perante si mesmo, será lembrar-se de uma parte e de outra que se foi, que ainda se é, e que não se pode deixar de ser Sujeitos" (LANDOWSKI, 2002, p.24). Estes sujeitos serão distintos, mesmo que haja algo impelindo sentidos na direção de uma suspensão de fronteiras entre identidades. Voigt passa a se entender diferente dentro de seu espaço de origem, por não ter prestado serviço militar, cria-se uma ruptura entre ele e seus pares da mesma geração, que é concretizada pela burocracia e intransponível sem o apelo ao símbolo de poder militar que é o uniforme de capitão. Somente lançando mão de uma mentira a personagem consegue se reinserir naquele espaço. Mas aí então, o que mais deseja é a autorização para deixar o local e se reinventar em outro espaço.

Tomaz Tadeu da Silva (2009) explica que questões de identidade e diferença estão estreitamente relacionadas às formas pelas quais a sociedade produz e utiliza classificações, o que também implica hierarquizar. "Deter o privilégio de classificar significa também deter o privilégio de atribuir diferentes valores aos grupos assim classificados" (SILVA, 2009, p. 82). Na comédia O capitão de Köpenick, Zuckmayer aponta a identidade militar tomada como norma e ocupando uma forma privilegiada de hierarquizar outras identidades e as diferenças naquela sociedade.

A normalização é um dos processos mais sutis pelos quais o poder se manifesta [...] Normalizar significa eleger - arbitrariamente - uma identidade específica como o parâmetro em relação ao qual as outras identidades são avaliadas e hierarquizadas. Normalizar significa atribuir a essa identidade todas as características positivas possíveis, em relação às quais as outras identidades só podem ser avaliadas de forma negativa (SILVA, 2009, p. 83).

Ainda que cercado por uma sociedade de adoradores da ordem militar e mesmo quando rejeitado na fábrica de sapatos em que estava quase conseguindo o emprego por não ter servido ao Exército, Voigt nunca deseja fazer parte da instituição. O deslocamento em que se encontra só faz com que reflita sobre o estopim da injustiça e da diferença que se criou entre ele e seus compatriotas. Quando compra o uniforme de capitão em uma loja de fantasias e finge, o objetivo final é o passaporte para poder escapar do espaço opressor. Apesar de distanciado, 
essa personagem nunca tenta se camuflar no grupo de referência, como faz o judeu dono da alfaiataria. As aspirações de Voigt seguem sendo da ordem do individual, da sobrevivência. Por fim, a personagem que busca ao longo de trinta anos afirmar sua identidade, acaba por se ver refletido no espelho da delegacia, não mais como o oprimido, mas então como o opressor uniforme de capitão. A resposta só poderia ser a gargalhada.

\section{REFERÊNCIAS}

HALL, Stuart. A identidade cultural na pós-modernidade. Tradução Tomaz Tadeu da Silva e Guacira Lopes Louro. Rio de Janeiro: DP \& A, 2006.

LANDOWSKI, Eric. Presenças do Outro: Ensaios de Sociosemióica. São Paulo: Perspectiva, 2002.

SILVA, Tomaz Tadeu. Identidade e diferença: a perspectiva dos estudos culturais. Tomaz Tadeu da Silva (Org.). Stuart Hall, Kathryn Woodward. Petrópolis, RJ: Vozes, 2009.

ZUCKMAYER, Carl. El capitán de Köpenick. Tradução Luis Novasterra. Buenos Aires: Ediciones Losange, 1957. 